\title{
MATRIZ DE VANTAGENS COMPETITIVAS SISTÊMICAS DA REgIÃo METROPOLITANA DE CURITIBA
}

\author{
Mariano de Matos Macedo ${ }^{1}$ \\ Wilhelm Eduard Milward de Azevedo Meiners ${ }^{2}$
}

\section{COMPETITIVIDADE SISTÊMICA REGIONAL}

O debate da competitividade regional se insere em um arcabouço teórico que ganhou grande ênfase a partir da segunda metade dos anos $80 \mathrm{e}$ ao longo de toda década de 90 , impulsionado por transformações nos cenários econômicos que demandavam ganhos de competitividade para as empresas como condição para sua sobrevivência. A crescente abertura comercial, produtiva e financeira, impulsionada pela nova ortodoxia neoliberal, proporcionou tanto um aumento da concorrência externa (seja empresas tentando buscar mercados fora de sua área base ou empresas defendendo suas posições perante a entrada de produtos e empresas de outras regiões), como um novo fluxo de investimentos diretos externos. Tais vetores foram impulsionados, por um lado, pela queda de rentabilidade das empresas nas áreas e setores de industrialização tradicional e, por outro lado, pelas possibilidades abertas pelas novas tecnologias de informação, comunicação e transporte. Aliás, a aceleração do progresso das tecnologias físicas que, ao lado da difusão de novas tecnologias de gestão associadas ao toyotismo seja a produção denominada flexível, enxuta ou de alta performance ,- configuraram um novo paradigma técno-econômico de proporções de uma Revolução Industrial. Fechando os vetores da transformação, são estabelecidas novas relações entre Estado-Sociedade. Se elas significaram a retirada do

Tecpar.

${ }^{1}$ Prof. do Departamento de Economia da UFPR e Diretor Presidente do

${ }^{2}$ Doutorando em Desenvolvimento Econômico pela UFPR. 
Estado nas funções de produtor, investidor, empreendedor e provedor de infra-estrutura e bem-estar, reforçaram suas funções de regulador e promotor das atividades econômicas e sociais, engendrando uma transição do planejamento e operacionalização das políticas públicas, para padrões onde predominam os fundamentos da descentralização, horizontalidade, seletividade e territorialidade das políticas, participação dos atores sociais (steakholders) e policies networks.

Nesse ambiente, as estratégias darwinianas de sobrevivência e evolução das espécies - competição, cooperação e inovação - são mais uma vez transmitidas ao plano econômico, permeando tanto firmas, como regiões e países.

Cabe fazer uma importante ressalva inicial sobre a necessidade de distinguir a competitividade regional/nacional da competitividade empresarial. Como destacou Paul Krugman (1997, p. 6):

\begin{abstract}
... tentar definir a competitividade de uma nação é muito mais problemático do que definir de uma empresa. O fundo do poço para uma empresa é falência: se uma empresa não conseguir pagar seus trabalhadores, fornecedores e detentores de títulos, fechará as portas. assim, quando dizemos que uma empresa não é competitiva, queremos dizer que sua posição de mercado é insustentável - que, caso não melhore o desempenho, irá à falência. Os países, por outro lado, não "fecham as portas". Eles podem estar satisfeitos ou insatisfeitos com seu desempenho econômico, mas não tem falência bem definida. Como resultado, o conceito de competitividade nacional é enganoso.
\end{abstract}

A crítica de Krugman se dirige àqueles que pretendem, a partir de uma visão distorcida de competitividade das nações, sustentar políticas de competição comercial ou de embate econômico, (como Lester Thurow em Cabeça a cabeça: a batalha econômica entre Japão, Europa e Estados Unidos). $\mathrm{O}$ autor indica que a competitividade nacional deva se traduzir mais corretamente em ganhos e promoção da produtividade. É nesse sentido que este texto se refere à competitividade regional. A competitividade de uma região pode ser definida sinteticamente como o conjunto de vantagens que ela oferece para a eficiência e eficácia de sua base produtiva. Porém, tal conjunto de vantagens não decorre somente de fatores estritamente econômicos que interferem nas condições e custos de investimento, da produção, de transação e na produtividade das empresas, mas também de variáveis que indicam a sustentabilidade dessas condições, incorporando elementos sociais, tecnológicos, ambientais e institucionais. 
A globalização ressalta as territorialidades por pelo menos duas óticas: por uma lado, é dada maior importância para o tecido social local (expresso nos contextos sociais e instituições locais); por outro, as atividades econômicas, em um ambiente de maior integração espacial, buscam as localidades mais lucrativas, o que conduz para a dimensão regional os fatores que suportam tal rentabilidade, "recriando o local e aumentando a competição local". ${ }^{3}$

As vantagens competitivas regionais devem ser percebidas dentro de um sistema de interações em diferentes níveis, que resultam na competitividade regional. De acordo com economistas do Instituto Alemão de Desenvolvimento (IAD) - Klaus Esser, Wolfgang Hillebrand, Dirk Messner e Jörg Meyer-Stamer -, os fatores determinantes da competitividade sistêmica ${ }^{4}$ podem ser distribuídos em quatro níveis:

a) Nível Meta: que revela a capacidade política de regulação e condução da economia, a integração social e a existência de padrões de organização que permitam mobilizar a capacidade criativa da sociedade. "Systemic competitiveness without social transformation is a futile endeavor." (ESSER et al., 1996, p. 23). No nível meta, destacam-se os fatores socioculturais, a escala de valores, os padrões básicos de organização política, jurídica e econômica e a capacidade de formular estratégias e implementar políticas;

b) Nível Macro: refere-se à estabilização macroeconômica capaz de manter um contexto adequado de política orçamentária e fiscal (gastos e impostos), política monetária (taxa de juros e crédito), política comercial e cambial (taxa de câmbio), compatíveis com os objetivos e metas de competitividade. Não há projeto empresarial que sobreviva a contextos inflacionários e de desajustes persistentes do orçamento, juros e câmbio;

c) Nível Micro: que compreende as empresas e organizações produtivas setoriais, que definem sua competitividade pela capacidade de gestão, pelas estratégias empresariais de inovação e conquista de market share, pela gestão da inovação, pela organização que privilegie as melhores práticas do ciclo completo do produto (desenvolvimento, produção e comercialização), pela integração em redes de cooperação tecnológica, pela logística empresarial e pela interação entre fornecedores, produtores e usu-

${ }^{3}$ DINIZ, C. C., 2000, p. 4 e MARKUSEN, A., 1996.

${ }^{4} \mathrm{O}$ sistêmico, neste caso, é entendido como processo de interação e reciprocidade entre o todo e suas partes. 
ários. Nesse sentido, cabe destacar que a competitividade, mesmo em nível micro, não é tarefa isolada da empresa, mas um fator sistêmico, pois:

Las crecientes exigencias a las empresas van de la mano con requerimientos cada vez mayores a su entorno. Las empresas que actúan en el mercado mundial ya no compiten de una manera descentralizada y hasta aislada, sino como conglomerados industriales, es decir, como grupos empresariales organizados en redes de colaboración. La dinámica de su desarrollo depende en gran medida de la eficacia de cada una de las localizaciones industriales, vale decir, del contacto estrecho y permanente con universidades, instituciones educativas, centros de investigación científica e tecnológica, instituciones de información y extensión tecnológicas, entidades financieras, agencias de información para la exportación, organizaciones setoriales no estatales y muchas otras entidades más. (ESSER, K. et al., p. 44)

d) Nível Meso: articulado entre o Estado e o mercado, rompendo as dicotomias tradicionais entre o público e o privado por meio das policies networks, ${ }^{5}$ políticas definidas no âmbito de redes horizontais de negociação interorganizacional, com a finalidade de garantir as crescentes exigências da competitividade internacional à região.

Resulta, pues, que la estructuración del nivel meso es ante todo un problema de organización y gestión De lo que se trata es de establecer una estructura institucional (hardware) y de promover en especial la capacidad de interacción estrecha entre actores privados y públicos al interior de un conglomerado (software) (...) En las regiones involucradas van surgiendo complejas redes de colaboración que engloban a organizaciones empresariales, sindicatos, asociaciones, administraciones locales, institutos tecnológicos y universidades. Esas redes se sitúan entre el Estado y el mercado; elaboran visiones o, en términos más pragmáticos, escenarios para el desarrollo regional; preparan decisiones estratégicas fundamentales y posibilitan una gestión política no

${ }^{5}$ De acordo com MARIN e MANITZ, citado por MACEDO, M. (1994, p. 76-77), policy network "não se refere mais a uma 'formação de rede' entre personalidades individuais, a conluios de grupos, à interligação de 'panelinhas', elites, partidos ou facções de classes, como nas tradições mais antigas, e sim à ação coletiva de agentes organizados e corporativos e, conseqüentemente, às relações inter-organizacionais no estabelecimento de políticas públicas". 
estadista de los programas de reconversión económica, así como la formación participativa de estructuras a nivel de localización industrial tanto regional como nacional. (ESSER, K. et al., p. 45-46)

A localização é um elemento importante para explicar a competitividade de uma empresa. A existência de fatores de localização sempre permearam o debate sobre o desenvolvimento regional e as razões de algumas regiões destacarem-se no cenário nacional e internacional na atração de empresas e na fertilização de empreendimentos inovadores.

Para uma análise dinâmica, é fundamental perceber que as vantagens competitivas regionais não devem se restringir a fatores localizacionais que são herdados, ou preexistentes em uma região, como sua dotação de recursos naturais e disponibilidade de matéria-prima, mão-de-obra abundante e barata, fatores climáticos e de fertilidade do solo, proximidade de centros consumidores e infra-estrutura de energia, comunicação e de escoamento da produção.

Porém, a existência de um conjunto de fatores que compõe as vantagens de localização industrial de uma região deve ser vista como condição necessária, mas não suficiente para a obtenção de vantagens competitivas regionais. De acordo com Allen Scott e Michael Storper (1988), os fatores localizacionais tradicionais omitem totalmente o problema principal das dinâmicas evolutivas internas dos complexos de crescimento. Os autores, focando as indústrias de alta tecnologia, destacam como principais as forças da divisão do trabalho na produção, na estrutura da atividade de transação entre estabelecimentos, e nas diferentes economias de aglomeração que surgem endogenamente em relação às formas de desenvolvimento localizado.

Georges Benko (1996, p. 133-135) chama atenção que, para a definição de uma teoria geral de localização é insuficiente ficar apenas em uma enumeração de fatores. Ainda que se destaque novos fatores de localização (em contraposição aos fatores clássicos weberianos), tem-se uma visão parcial, pois são elementos necessários, porém insuficientes para explicar a dinâmica dos novos espaços industriais. Ademais, o autor considera que não há uma combinação adequada de fatores de localização para todos os ramos industriais ou para todos os portes empresariais. Porém, mesmo assim, destaca que alguns fatores são comumente explicitados em vários casos, representando os fatores de localização para a indústria de alta 
tecnologia. Poderia-se denominá-los sinteticamente de novos fatores de localização: ${ }^{6}$

- Força de trabalho (capital humano) - capacidade de atrair e conservar trabalhadores, divididos em dois grupos: os executivos (cientistas, engenheiros e administradores) e a mão-de-obra barata para a produção. Essa dualidade funcional requer algumas características do lugar: por um lado, o lugar deve ser percebido como agradável para atrair e conservar os executivos e, por outro lado, o mercado de trabalho deve ser amplo e disponível para as demais categorias, com destaque a questões como a oferta de trabalho, taxa de salário e sindicalização;

- Universidades, institutos de pesquisa e infra-estrutura tecnológica: respondem diretamente às demandas de ensino, mão-de-obra de alta qualificação em serviços avançados e a possibilidade das equipes locais colaborarem na pesquisa industrial;

- Infra-Estrutura: acesso fácil e rápido para as pessoas, com destaque às facilidades e conexões do transporte aéreo para atividades de ponta aeroporto internacional; e baixo custo de transporte - para as atividades tradicionais; sistema de telecomunicações por satélites, redes locais de fibra ótica e internet de banda larga; hotéis de luxo com segurança adequada;

- Economias de Aglomeração: destaque para os spin-offs que as grandes empresas e a densidade das aglomerações geram pela facilidade de formação de redes de informação e contatos "frente a frente", permitindo a fertilização cruzada de negócios; para os efeitos de escala no mercado de trabalho (facilitando a rotação - mobilidade - de mão-de-obra) e na infraestrutura (concentração de empresas em um único espaço reduz custos fixos proporcionais dos investimentos em infra-estrutura); e para o aprofundamento na divisão social do trabalho, com maiores possibilidades de especialização produtiva da localidade;

- Serviços e Clima de Negócios: presença de empresas financeiras, consultores especializados com conhecimento da região, serviços de assistência secretarial em língua estrangeira, fontes (e sistemas de circulação) de informação, liberdade para a produção, sindicalização fraca e a disponibilidade de capital de risco (venture capital). Neste aspecto, o papel dos poderes públicos é também ressaltado pelas facilidades de providências administrativas, acesso a informações, infra-estrutura de apoio e políticas de fomento empresarial;

37.

${ }^{6}$ De acordo com BENKO, G., 1996; BORJA, J. e CASTELLS, M., 1997, p. 
- Atrativos da paisagem: envolve as condições de moradia (inclusive preço), o acesso à infra-estrutura cultural e de ensino e a existência de um ambiente moderno, limpo, seguro, com variedade de equipamentos de lazer, capaz de atrair os executivos.

Estes dois últimos elementos mereceram um comentário particular de Benko, com uma conotação especial para a atratividade da região, com as prerrogativas de Desenvolvimento com Qualidade de Vida: ${ }^{7}$

... a atração de uma região, geralmente caracterizada pela "qualidade de vida", não é nem uma categoria universal nem uma constatação histórica, mas uma realidade politicamente construída. Esse dado qualitativo não é tampouco condição preexistente, mas atributo social e político essencial para os produtores - ideologicamente definido pelos consumidores que pode promover crescimento industrial. A criação do quadro de vida para a vida dos [ quadros] executivos [cadre de vie pour la vie des cadres] acompanha-se de conotações precisas: densidade fraca, habitações confortáveis, vida familiar privatizada e abundância de recursos de lazer. ${ }^{8}$ Para os capitalistas, a qualidade do ambiente está associada a um clima de negócios que representa imposição favorável, ausência de sindicalização e a liberdade de desenvolver a produção e o mercado de trabalho.(BENKO, G., 1996, p. 147).

A localização é um dos elementos importantes para definir a competitividade da firma, com vantagens decorrentes da concentração de atividades econômicas na região, na forma de clusters ou arranjos produtivos. Estas vantagens são sinteticamente de três tipos: economias de aglomeração, economias de aprendizado por interação e ganhos de eficiência coletiva.

${ }^{7}$ Não é sem propósito que o material básico de divulgação empresarial de Curitiba nos anos 90, editado pela Companhia de Desenvolvimento e pela Secretaria Municipal da Indústria e Comércio, que ressaltava suas vantagens de localização e apresentava a região para os investidores nacionais e estrangeiros, chamava-se Curitiba: Desenvolvimento com Qualidade de Vida.

${ }^{8}$ Tem-se uma descrição sucinta dos condomínios de alta renda (completando o quadro com a existência de sistemas sofisticados de segurança privada), que afloram nas cercanias das regiões metropolitanas mais dinâmicas, na América Latina e em outras regiões periféricas, firmando-se como um fenômeno praticamente universal na solução de moradia para os quadros executivos das grandes empresas transnacionais. Soluções que procuram criar um quadro de vida semelhante ao que tais executivos presenciam nos subúrbios das metrópoles européias e norte-americanas. 
Pode-se descrever as economias de aglomeração como vantagens ou economias externas à empresa individual, que propiciam reduções de seus custos e ganhos de produtividade, em função do grau de concentração espacial das atividades econômicas, mão-de-obra, indústrias correlatas, redes de fornecedores, serviços ligados à produção, agentes de $\mathrm{P} \& \mathrm{D}$ e atividades urbanas, em geral. A localização da empresa em uma aglomeração afeta sua vantagem competitiva por meio da influência positiva sobre os seus níveis de produtividade, em especial, pela qualidade do ambiente de negócios, expressa em:

- acesso a insumos e serviços especializados (de maior qualidade e menor custo);

- constituição de um mercado de trabalho local especializado, com elevada mobilidade e oferta abundante e diversificada (diferentes perfis) de força de trabalho qualificada e treinada, conformando uma bacia de empregos flexível para as empresas;

- proximidade a serviços especializados, pois os processos de produção mais complexos de serviços corporativos, sobretudo em setores inovativos, requerem múltiplos insumos especializados. A criação de uma inovação financeira, por exemplo, requer insumos de contabilidade, publicidade, designers, perícia legal, consultorias econômicas, relações públicas, designers de softwares, etc.;

- fornecimento local, o que minimiza a necessidade de estoque, elimina custos e tempo de transporte, permite a introdução de sistemas de quase-integração vertical, com maior transparência das alianças, facilidade das comunicações pessoais (face a face), redução dos custos de personalização e co-design dos produtos e correção de falhas;

- acesso à informação: fluxos e acumulação de informações técnicas, de mercado e sobre outras áreas especializadas (com maior qualidade e baixo custo);

- complementaridades: interdependência de setores afins, marketing conjunto, aumento da eficiência para o comprador (visitação a várias empresas na mesma localidade);

- acesso a instituições e benefícios públicos: programas locais de treinamento especializado, infra-estrutura especializada, pools de informação e tecnologia;

- incentivos e mensuração do desempenho: pressão competitiva para obter ganhos de produtividade e padrões de comparação próximos.

$\mathrm{O}$ reconhecimento da influência das economias externas sobre empresas e negócios de uma região é um capítulo importante das teorias clássicas de economia regional. Em uma versão moderna dessas teorias, formulada por Azzoni (1982 e 1985), a região possui dois fatores-chave na 
determinação da localização industrial: a produtividade e o custo da mão-deobra. Eles são os principais determinantes da produtividade e da rentabilidade que a empresa pode obter em uma região. Nesses dois fatores se incorporam todos os elementos que favorecem a ampliação da produtividade da mão-de-obra, como o nível de escolaridade e as condições de vida das famílias, ou a redução do custo salarial, como sistemas de serviços sociais eficientes que permitam menores gastos com transporte, saúde, educação, alimentação, moradia, comunicação, etc. Agregam-se a esses dois fatores fundamentais para definição da produtividade empresarial e das vantagens de localização, os sistemas de infra-estrutura que possibilitem maior acessibilidade e conectividade da região, bem como os incentivos fiscais concedidos.

Porém, ainda que a análise de vantagens comparativas seja importante para expressar formalmente os fatores de localização industrial em uma região, eles não dão conta dos elementos dinâmicos que influenciam a competitividade empresarial e, nesse sentido, são limitados a uma percepção estática. $^{9}$

Nesse sentido, cabe fazer a relação necessária entre a mudança nos paradigmas tecno-econômicos e a reconfiguração dos espaços para a produção, definindo novo sentido de aglomeração, para a busca de vantagens competitivas dinâmicas.

A organização da produção em muitos segmentos industriais, inclusive a indústria eletrônica e a automobilística, está observando crescente processo de desintegração vertical (ou complexos industriais de produção articulados, conformando uma quase-integração vertical) dada à obtenção de eficiência crescente em empresas dedicadas a um conhecimento específico da atividade, a partir inclusive de novas tecnologias de automação flexível.

9 “Las nuevas orientaciones sobre la construcción de las ventajas competitivas regionales deben ir más allá de las "vantajas comparativas", y llegar a compreender los determinantes de las vantajas competitivas dinámicas, esto es, deben incluir un rico conceptp de competencia (y no sólo los elementos relativos ao costo de los factores), en el que la diferenciación de los produstos, la segmentación de los mercados, las economias de escala y de diversidad (o de gama), la construcción del entorno de servicios avanzados a la producción, sean introducidos. Este nuevo enfoque debe considerar también que la competencia es evolutiva (o dinâmica), reconociendo entonces como elementos fundamentales la mejora y la inovación en los métodos y la tecnologia." (ALBUQUERQUE, F., 1995, p. 24). 
Qualquer que sejam as razões para a desintegração vertical dos processos de trabalho, ela tende a criar retornos crescentes via economias externas, isto é, queda constante dos custos de produção, resultante da especialização das firmas. Isso também foi o que Young (Increasing returns and economic progress, 1928) tão oportunamente chamou de roundaboutness crescente da produção. O roundaboutness pressupõe a criação de complexos industriais organizados em termos de uma estrutura cada vez mais elaborada de relações transacionais entre as indústrias, incluindo contatos face-à-face e trocas pormenorizadas de informações estratégicas, subcontratação e recontratação de curto e longo prazos, fluxos materiais insumoproduto, e assim por diante. Essas relações transacionais freqüentemente têm estruturas de custo geograficamente dependentes. Quanto maior for o valor destes custos por atividade transacional, maior será a probabilidade dos fabricantes envolvidos em compromissos transacionais mútuos se aglomerarem, a fim de reduzi-los. (SCOTT e STORPER, 1988, p. 35)

Apesar de todo o avanço nas redes neurais empresariais, redes telemáticas e sistemas intranet, bem como nos sistemas de transporte multimodais, há tanto custos de transação referidos ao espaço (relações não padronizadas que necessitam de renegociação intensiva; articulações constantes que envolvem transporte de pequena escala, tipo JIT; e articulações problemáticas que requerem ajustes contínuos, contatos face-à-face e negociações freqüentes e imprevisíveis), como aumento de roundaboutness, gerando intensificação nas reaglomerações e reconcentração espacial, definindo espaços privilegiados para a localização de atividades industriais correlacionadas, independente das vantagens exógenas que a região possa oferecer.

As vantagens de aglomeração, definidas em nível microdinâmico, também se reportam à formação de um mercado de trabalho local. Normalmente, os complexos localizados de produção industrial atraem para sua órbita espacial bolsões de mão-de-obra que representam mais ou menos o conjunto de qualificações necessárias pelo complexo. Esse fato deriva tanto de uma qualificação on site em diferentes firmas complementares e interrelacionadas (compartilhadas pelos demais quando há uma taxa de rotatividade entre empresas do mesmo grupo), como da instalação de instituições de ensino e extensão em especialidades adequadas, o que permite a qualificação e a pesquisa aplicada relevantes ao sistema industrial local: "Assim, eles se tornam elementos endógenos importantes de todo processo 
de reprodução territorial local. Quando estas instalações são fornecidas ou subsidiadas pelo poder público, os fabricantes têm a vantagem da desprivatização de pelo menos parte dos custos de treinamento, pesquisa básica e desenvolvimento." (sCOTT e STORPER, 1988, p. 36) Desse modo, é fundamental que as vantagens de localização se coloquem como um fator endógeno, desenvolvido a partir do ambiente em consolidação pelo sistema industrial regional.

A existência de economias de aglomeração explicam também a geografia dos novos espaços industriais. Segundo Georges Benko (1996, p. 124 et seq.), em uma nova estrutura urbana e regional, em que se destaca a emergência de novos setores de crescimento, baseadas nas tecnologias de informação e comunicação, nas atividades de criação e de direção e nos serviços financeiros, jurídicos e imobiliários, algumas regiões se distinguem, pelas economias de aglomeração associadas à flexibilidade da produção e relações interempresariais e à flexibilidade do mercado de trabalho. É o caso das regiões baseadas na aglomeração de atividades artesanais revitalizadas, nos aglomerados de complexos industriais de ponta, ou nas metrópoles, que oferecem um elevado grau de concentração de serviços superiores às empresas. No caso das metrópoles, Benko (1996, p. 127) lembra que:

É igualmente notório que as grandes metrópoles são os principais nós das redes físicas e informáticas e das redes de telecomunicações, as sedes das organizações financeiras, comerciais e industriais que se encarregam da realização e da valorização do capital. São assim os núcleos de um novo espaço de fluxos. Foi nessas cidades e na rede hierárquica complexa das cidades de importância menor que as cercam que se desenvolveram as atividades de serviços, e foi o desenvolvimento diferenciado dessas grandes cidades que desempenhou papel maior na produção de novo mapa do desenvolvimento regional.

Sobre esta mesma questão, Saskia Sassen destaca que as indústrias de informação superior estão elevando a demanda por novas formas de concentração territorial da gestão de alto nível e do controle das operações, além de requererem uma vasta infra-estrutura física, com ênfase na hipermobilidade e na hiperconcentração de serviços especializados ao produtor. Desta forma, as cidades emergem em uma nova geografia da centralidade, conformando uma malha de locais estratégicos, ou uma malha metropolitana de nódulos urbanos de diferentes níveis e funções, conectados 
a partir de redes telemáticas, que se estende por todo o planeta - a cidade global. ${ }^{10}$

Ainda que as novas tecnologias de informação e comunicação tornem possível uma maior dispersão de unidades produtivas, centros de gestão, criação e comércio, o mundo continua organizado em uma rede de centros de decisão e direção baseados em aglomerações de espaços limitados, com saturação nos sistemas de infra-estrutura de transporte e comunicações, sobrevalorização de áreas, preço maior para oferta de serviços públicos e maior restrição das políticas urbanas. Conforme destaca Sassen (1998, p. 4):

la combinación de dispersión geográfica de las actividades económicas y de integración del sistema, que descansa sobre el corazón de la actual era económica, ha contribuido con nuevas o ampliadas funciones centrales, y la complejidad de las transacciones ha hecho aumentar la demanda de servicios altamente especializados por parte de las empresas. Más que volverse obsoletas debido a la dispersión detonada por las tecnologías de información, las ciudades: a) concentran funciones de comando; b) son sitios de producción postindustrial para las industrias líderes de este período, financieras y de servicios especializados; y c) son mercados transnacionales donde las empresas y los gobiernos pueden comprar instrumentos financieros y servicios especializados.

Em segundo lugar, tem-se as economias de aprendizado por interação (learning by interaction). Pode-se expressá-las como os ganhos econômicos das empresas que surgem de relações duradouras com clientes ou fornecedores, criando um aprendizado coletivo para melhoria dos métodos de produção, qualidade dos produtos e maior capacitação tecnológica. Surge principalmente em entornos inovadores, (millieu inovateurs) que agrupam, em um todo coerente, um sistema de produção, uma cultura técnica e atores organizados (empresas, instituições de pesquisa, associações patronais e sindicais, etc.) que utilizam os recursos materiais e imateriais regionais, produzem e trocam bens, serviços e comunicações, formando uma rede de relações e vínculos de cooperação e interdependência. Em seu texto, Cuadrado Roura (1995, p. 21) chama atenção para o fato de que as empresas

${ }^{10}$ Ver SASSEN, S., 1998; BORJA, L. e CASTELLS, 1997. 
não nascem como "catedrais em um deserto", mas em um entorno (meio) inovador $^{11}$ que:

... es un microcosmos en el que actúan los elementos que normalmente suelen considerarse como fuente de creación del desarrollo económico y del cambio, los cuales se benefician del elemento de proximidad geográfica y de las homogeneidades económicas y culturales que permiten definir territorialmente el propio medio o entorno local/regional.

Georges Benko (1996, p. 140) resume esta concepção assim:

... a empresa inovadora não preexiste aos meios locais. É produzida por eles. Os comportamentos inovadores dependem de variáveis definidas no nível local ou regional. O passado dos territórios, sua organização, sua capacidade de fazer surgir um projeto comum e o consenso que os estrutura estão na base da inovação. Aqui, o acesso ao conhecimento tecnológico, a presença do know-how, a composição do mercado de trabalho e muitos outros componentes dos meios locais determinam zonas de maior ou menor receptividade à inovação.

No entorno inovador destacam-se os processos de aprendizagem coletiva - onde a inovação é vista como um fenômeno coletivo - decorrentes de intercâmbios de tecnologias de produto e processo, organização e comercialização, provisão de serviços especializados, fluxos de informação e estratégia dos atores regionais. Como destaca Francisco Alburquerque (1995, p. 23):

La creciente mundialización económica, al eliminar impedimentos al comercio con los que proteger las empresas y sectores interiores, esto es, al elevar el grado de exposición a la competencia de éstos, ha hecho resaltar al papel de la localización de las empresas en determinadas regiones, en la medida que éstas sean capaces de crear el "entorno" impulsor de innovaciones y perfeccinomaneo productivo. De este modo,

${ }^{11}$ Entorno inovador ou milieu innovateur, conforme abordagem desenvolvida por Cuadrado Roura (1995) e pesquisadores do Gremi (Groupe de Recherches sur les Milieux Innovateurs), sobretudo AYDALOT, P. Milleux Innovateurs en Europe. Paris: Gremi, 1986. 
las ventajas competitivas dinámicas se crean y se mantienen mediante un proceso altamente localizado. Ello depende de que el correspondiente "espacio" geográfico regional o local se constituya en "territorio" y entorno fértiles.

Existiria, nesse sentido, uma disposição regional, com elementos inerentemente localizacionais, para o surgimento e crescimento de empresas inovadoras. Nesse sentido, as economias externas ou de distrito se destacam na medida em que reduzem desvantagens nos custos de pequenas empresas locais, além de ajudá-las no processo de inovação; as economias de proximidade, que reduzem custos de transação e ampliam o fluxo de informações; e elementos sinérgicos: processos de imitação, interação entre agentes locais para projetos de infra-estrutura e serviços, colaboração entre usuários e fornecedores, integração entre centros de pesquisa e empresas inovadoras, etc. Ganha importância a formação de alianças estratégicas entre os diferentes atores regionais em redes de cooperação entre empresas, instituições de pesquisa e instituições públicas para a articulação em torno de projetos tecnológicos, educativos ou de infra-estrutura (CUADRADO ROURA, 1995, p. 24). Conforme Esser et al., (1996, p. 44) tais elementos espaciais refletem na competitividade das empresas, uma vez que

Las crecientes exigencias a las empresas van de la mano con requerimientos cada vez mayores a su entorno. Las empresas que actúan en el mercado mundial ya no compiten de una manera descentralizada y hasta aislada, sino como conglomerados industriales, es decir, como grupos empresariales organizados en redes de colaboración. La dinámica de su desarrollo depende en gran medida de la eficacia de cada una de las localizaciones industriales, vale decir, del contacto estrecho y permanente con universidades, instituciones educativas, centros de investigación científica e tecnológica, instituciones de información y extensión tecnológicas, entidades financieras, agencias de información para la exportación, organizaciones setoriales no estatales y muchas otras entidades más.

Tanto as economias de aglomeração como o aprendizado coletivo ( BOISIER, 2001) requerem uma forte dose de capital social, traduzido em redes de cooperação baseadas na confiança interpessoal, capazes de operar em contexto de operacionalidade difusa, além de relações familiares e de amizade, orientadas para a consecução de fins legítimos. Nesse sentido, pode-se perceber o terceiro tipo de vantagens de uma região: a eficiência coletiva. 
Essa eficiência é uma combinação de dois efeitos: primeiro, surge da interrelação entre as economias de aglomeração e economias de aprendizado por interação; segundo, reafirma-se a partir da cooperação privada e apoio público em ações deliberadas. A eficiência coletiva enfatiza também o papel das organizações de integração, fomento e articulação nas regiões.

Finalmente, é importante destacar a missão de transcender à dicotomia estatal-privado, pois o desafio de consolidar o desenvolvimento de uma região é superior, nas condições atuais, à capacidade financeira e empresarial do Estado. Nesse sentido, deve-se partir para a formação de policies networks, com definições compartilhadas de competências e recursos regionais para a construção de um programa sinérgico de articulações. O Estado se retira, mas mantém a motivação e coordenação dos vínculos entre os agentes econômicos, organizando o espaço produtivo e os sistemas de apoio. Por um lado, as interações próprias do sistema produtivo, articulando complexos industriais regionais, e, por outro, a participação de instituições de fora (bridging institutions, agências governamentais, consumidores, etc.), como conjunto de atores sentados em uma mesa redonda de negociação e definição de estratégias, recursos e instrumentos para inserção competitiva da região.

Não cabem mais definições de cima para baixo, sem concertação social, onde a política industrial de gabinete define as especializações e o alcance de programas e recursos federais/estaduais para a promoção regional. É cada vez mais urgente para as regiões o desenvolvimento de um esforço de comando sobre seus próprios recursos, e negociação de recursos externos, para atender a suas estratégias e agências regionais próprias.

Dessa forma, uma região deve se colocar como sujeito de seu desenvolvimento, e não ser um objeto solto de incidências de políticas setoriais genéricas. Cabe aqui a percepção de Sérgio Boisier (1992) de regiões como Quase-Estado, configurando a necessidade de maior autonomia e descentralização do poder para a mobilização social em torno de projetos para a região:

En este contexto, un gobierno regional no sólo requiere trabajar coordinadamente con la sociedad civil regional (y en particular con el sector empresarial); la conducción estratégica del gobierno regional debe ir más allá de la especificación del conjunto de cuatro pares de variables anotadas, debe asociarse fuertemente a la conformación de aglomerados sinérgicos, a la creación de redes interactivas y a la construcción de infraestructura moderna que facilite la competitividad. (BOISIER, 1992, p. 184) 
Assim como as economias nacionais, pode-se afirmar as regiões competem entre si, para estarem inseridas de maneira privilegiada nos fluxos de capital, investimento, emprego e tecnologia. Com a eliminação crescente das barreiras comerciais, traço característico da globalização, a competição entre regiões, pela manutenção de seus postos de trabalho, pela captação de novos investimentos, pela dotação de infra-estrutura física e tecnológica, se amplia. Esser et al. (1996, p.140) destacam que

\begin{abstract}
Es justo señalar, sin embargo, que un entorno deficiente no impede en principio la creación de competitividad. Cuando las condiciones generales cambian básicamente con el paso de un mercado interno protegido a una economía abierta y cuando las empresas se ven ante la disyuntiva de elevar su eficiencia o salir del mercado, por lo menos una parte de ellas hace los esfuerzos necesarios para mejorar con rapidez su competitividad. Esto se logra en primer término ali donde es factible aprovechar determinadas ventajas estáticas de localización. Pero la ausencia de un entorno eficaz restringe la capacidad de las empresas para lograr una competitividad duradera. Sucede que éstas no pueden concentrarse en la actividad productiva central que las hacen competitivas porque se ven obligadas a desarrollar por sí mismas las producciones y los servicios internos que otras empresas poden adquirir ou explotar en cualidad de externalidades. En consecuencia, no se produce en ellas el mejoramiento que distingue a las empresas de eficiencia duradera.
\end{abstract}

A capacidade dos fatores sistêmicos de influenciar a competitividade empresarial é o que orienta as empresas no momento de decidir a localização de um novo investimento. Nesse sentido, buscam-se regiões com fatores de localização que ampliem a performance empresarial na geração de maior valor adicionado, menores custos de produção e favoreçam o posicionamento estratégico da empresa na trajetória dos paradigmas tecnológicos dominantes.

São nesses parâmetros que se colocam os desafios da construção das vantagens competitivas regionais, de caráter sistêmico, cumulativo, e dinâmico, demandando de qualquer região uma resposta articulada para sua inserção ativa na competição globalizada, sob o risco de se manter como periférica e retardatária, incorporando a necessidade de manter-se sustentável nas condições sociais, políticas e ambientais. 


\section{PROCEDIMENTO METODOLÓGICO}

O exercício de construção de uma matriz de vantagens competitivas sistêmicas de uma região leva em consideração a conjunção do impacto de uma série de fatores considerados como determinantes das suas condições de competitividade. ${ }^{12}$

O conhecimento dos direcionadores e a sua classificação quanto ao grau de controlabilidade, bem como a avaliação da medida em que impactam as vantagens competitivas da região, são condições essenciais para o estabelecimento de políticas públicas e estratégias institucionais e empresariais com vistas a orientar o planejamento estratégico regional.

A especificação das condições, direcionadores e subfatores da competitividade sistêmica regional tem por base as análises de Porter e Christensen (1999), Mckinsey e Company/FIEMG (2000), Prokopenko (2000), Esser et al. (1996) e Van Duren et al. (1991), GEM (Global Entrepreneurship Monitor), Gremi (Groupe de Recherche Europeén sur les Milieux Innovateurs), JCCI-Jacksonville/AVIA Internacional, e Gepai (Grupo de Estudos da Produção Agroindustrial)/UfSCAR (2002).

O processo de elaboração e avaliação de uma Matriz de Vantagens da região, segundo direcionadores de competitividade sistêmica, pode ser esboçado segundo as seguintes etapas principais:

a) A primeira etapa envolve a definição dos direcionadores de competitividade. A competitividade sistêmica regional incorpora, como apresentado na primeira parte deste artigo, muitos temas relevantes. A seleção dos direcionadores é feita pela importância desses temas para explicar a competitividade da região:

1. Infra-Estrutura

2. Base Empresarial

3. Clima de Investimentos

4. Mercado

5. Estrutura Urbana

6. Condição Social

7. Base Educacional

8. Condições e Relações de Trabalho

9. Sistema de Ciência e Tecnologia

10. Meio Ambiente

11. Ambiente Institucional

12 VAN DUREN, E.; MARTIN, L.; WESTGREN, R.,1991, p. 727-738. 
b) Cada direcionador, em uma segunda fase, é dividido em subfatores, de acordo com os elementos que estão incorporados aos direcionadores e explicam as suas condições de competitividade. Nesse sentido, há opções de construção em diferentes níveis de detalhamento: podese optar por reduzido número de subfatores, simplificando o escopo de análise e a obtenção de informações, porém com limitações na definição de políticas regionais, ou pela ampliação do número de subfatores, compreendendo, dentro de um nível mínimo de significância, os elementos mais expressivos que possam ser alvo de projetos e políticas específicas, mesmo com um nível de informação mais subjetiva e qualitativa. Optou-se pela segunda opção, em decorrência da complexidade dos temas propostos para análise. Assim os subfatores podem ser determinados diretamente por indicadores mensuráveis, dispostos nos censos demográficos, pesquisas de amostra domiciliar, indicadores de infra-estrutura e base de dados sobre a região, mas também podem ser obtidos indiretamente em variáveis passíveis de mensuração e ainda definidos com base em elementos qualitativos;

c) Na seqüência, cada subfator é classificado quanto ao seu grau de controlabilidade. Esta classificação é importante dado que permitirá, em etapa posterior, a associação de eventuais problemas ligados a um determinado subfator a agentes de intervenção específicos. Estes fatores são denominados como direcionadores de competitividade e podem ser divididos em quatro grandes grupos, segundo o grau de controlabilidade: (a) fatores controláveis pelas firmas e instituições privadas; (b) fatores controláveis pelo governo regional; (c) fatores pouco controláveis (que podem ser influenciados por uma ação regional, mas há uma capacidade de atuação direta muito baixa) e (d) fatores não controláveis, que estão fora do âmbito de ação dos agentes regionais. Ações de coordenação que visem aumentar a competitividade da região estão incluídas nos grupos (a), (b) e (c) simultaneamente, pois dependem de uma articulação entre firmas, instituições e governo regional, para serem efetivamente controláveis;

d) Uma quarta etapa envolve a atribuição de pesos relativos para cada subfator e direcionador de competitividade. A motivação para esse procedimento de ponderação é o reconhecimento da existência de graus diferenciados de importância dos diversos subfatores, em termos de sua contribuição para o desempenho agregado da competitividade sistêmica. Para a análise realizada optou-se por pesos semelhantes para cada um dos direcionadores;

e) Uma quinta etapa refere-se à avaliação qualitativa da intensidade do impacto dos subfatores e de sua contribuição para o efeito agregado dos direcionadores. Para tanto, é estabelecida uma escala do tipo 
"likert", variando de "muito favorável", quando há significativa contribuição positiva do subfator, a "muito desfavorável", no caso da existência de entraves ou mesmo impedimentos, a curto e médio prazos, ao alcance ou sustentação da competitividade. Como valores intermediários, são estabelecidas as categorias "favorável", "neutro" e "desfavorável". Essa escala é transformada em valores que variam progressivamente, em intervalos unitários, de -2 , para uma avaliação "muito desfavorável", a +2 , para "muito favorável". Deste modo, os resultados da avaliação podem ser visualizados em representação gráfica, bem como ser combinados quantitativamente, para comparações agregadas. ${ }^{13}$ Como conclusão dessa etapa, uma primeira versão da definição dos direcionadores e subfatores, da atribuição de seus pesos e da avaliação de suas contribuições para o agregado é realizada pela equipe técnica responsável pela elaboração da Matriz;

f) Uma sexta etapa refere-se à organização de um workshop técnico com o objetivo de validar os resultados encontrados pela equipe. Este evento permite uma revisão dos subfatores de competitividade considerados pela equipe, bem como da definição de seus graus de controlabilidade e de seus pesos e a avaliação de seus impactos na competitividade sistêmica da região. Nesse workshop é utilizada uma variante da metodologia "delphi", por meio da qual os participantes realizam avaliações individuais prévias, que são posteriormente discutidas e revistas até que um julgamento consensual seja conseguido.

\section{AVALIAÇÃO DA COMPETITIVIDADE SISTÊMICA DA REGIÃo METROPOLITANA DE CURITIBA}

Conforme a metodologia exposta acima, para a construção da matriz, parte-se dos onze direcionadores de competitividade e da definição de seus subfatores. As informações relevantes para a definição e avaliação dos

${ }^{13}$ Deve ser ressaltado que, a rigor, a utilização de escalas como a que será adotada permite, tão somente, o ordenamento e classificação relativa da intensidade dos subfatores analisados, não sendo totalmente apropriado o tratamento quantitativo dos valores atribuídos. No entanto, conforme observam Singleton et al. (Approaches to Social Research. New York: Oxford University Press, 1993, p. 114), é prática usual nas Ciências Sociais a suposição de que medidas ordinais, como a aqui proposta, são aproximações de intervalos iguais de medição. Aceitando-se essa premissa, pode-se então tratá-las quantitativamente. Exemplos de estudos que utilizam combinações quantitativas de valores ordinais são freqüentes nas áreas de localização industrial e análises de impactos ambientais. 
subfatores foram obtidas em estudos recentes sobre o desenvolvimento da $\mathrm{RMC}$ e em consultas a empresários de setores chaves da economia. ${ }^{14}$ Para a análise da RMC, adotou-se como referência padrões observáveis nas Regiões de Porto Alegre, São Paulo, Belo Horizonte, Campinas e São José dos Campos, definindo o escopo das condições mais favoráveis e mais desfavoráveis para cada subfator avaliado. Esta avaliação foi empregada como referência para a elaboração do Plano de Desenvolvimento Integrado da Região Metropolitana de Curitiba - Componente de Desenvolvimento Econômico ${ }^{15}$ facilitando a identificação de ações e a articulação de políticas públicas e privadas voltadas à promoção do desenvolvimento regional.

Os resultados da análise estão dispostos nas Matrizes elaboradas para cada direcionador, contendo os subfatores, o peso de cada subfator, a avaliação e o grau de controlabilidade, dispostos nas tabelas do Anexo 1. O resultado sintético está disposto no gráfico radar a seguir:

\section{Gráfico 1 - DIRECIONADORES DA COMPETITIVIDADE SISTÊMICA NA REGIÃO METROPOLITANA DE CURITIBA - condições de Infra-Estrutura}

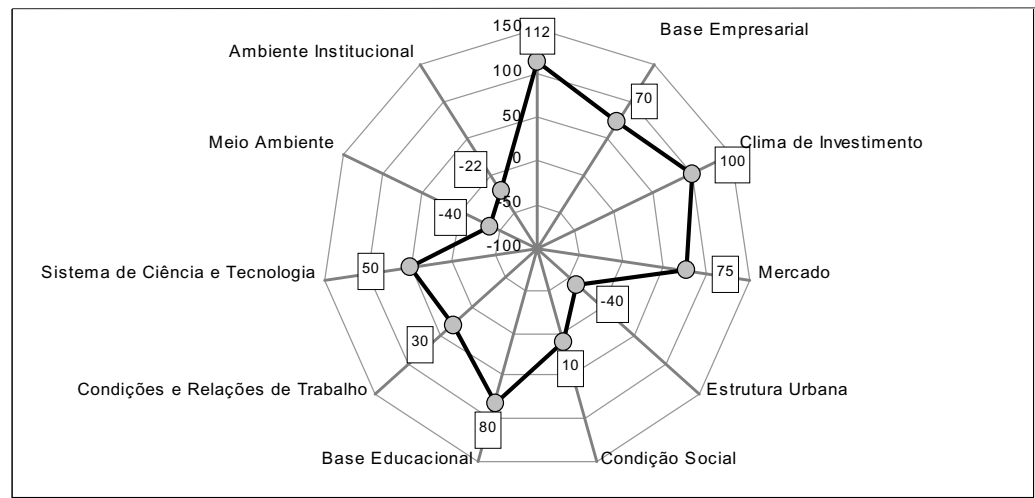

${ }^{14}$ Este exercício teve como principais referências: COMEC, 2001; CONSÓRCIO SOGREAH/COBRAPE/GROUPE HUIT, 2002; FIRKOWSKI, O., 2001; MOURA, R., 2000; MOURA, R.; KLEINKE, M. L. U., 1999; OLIVEIRA, D., 1995; IBGE, 2002a; IBGE, 2002b; IBGE SIDRA. Pesquisa de Informações Básicas Municipais; e IBGE.

${ }^{15}$ COMEC/COBRAPE/SOGEART. Plano de Desenvolvimento Integrado da Região Metropolitana de Curitiba. Curitiba: Comec, 2002. 
De acordo com a metodologia adotada, cada direcionador pode receber uma avaliação ponderada entre -200 (se todos os subfatores obtivessem uma avaliação Menos Favorável, -2) a + 200. Dos 11 direcionadores analisados, explicam favoravelmente a competitividade sistêmica da RMC as condições de infra-estrutura, o clima de investimentos e a base educacional.

$\mathrm{Na}$ infra-estrutura, os destaques mais favoráveis são a condição do sistema de comunicações, sobretudo a oferta e qualidade da telefonia fixa e móvel, a oferta e qualidade do suprimento de energia, sobretudo elétrica, e o funcionamento de um terminal alfandegário (Porto Seco). As deficiências são mais sentidas em relação às condições logísticas, de transporte de carga com o transporte ferroviário, o escoamento de carga do porto e a oferta de gás canalizado.

O clima de investimento vem sendo bastante positivo na região, pelo menos desde 1995, com a vinda de montadoras automobilísticas que engendrou um pesado fluxo de investimentos para a RMC, "puxando" investimentos em serviços, comércio e empreendimentos imobiliários. Também chama a atenção o nível de reinvestimento de grupos empresariais já instalados na região, o elevado grau de empreendedorismo local (ainda que seja entre as micro e pequenas empresas) e a percepção positiva dos instrumentos fiscais e financeiros de incentivo aos investimentos. Os pontos fracos nesse direcionador são: a baixa participação dos grupos regionais no fluxo de investimentos, o baixo grau de relacionamento dos novos investidores com a base produtiva local e uma condição desfavorável de incentivo aos grupos empresariais locais, elementos que enfraquecem a base empresarial da região. Na base educacional, a avaliação positiva foi puxada pelas condições favoráveis do ensino profissionalizante, pela oferta de escolas internacionais e pelo bom resultado de indicadores educacionais como a taxa de alfabetização funcional e taxa de escolarização.

As condições mais desfavoráveis na Região Metropolitana de Curitiba podem ser indicadas pelos três direcionadores de avaliação negativa: estrutura urbana, meio ambiente e condições institucionais. Na estrutura urbana, as situações mais críticas detectadas são: a disponibilidade e o acesso à propriedade de terrenos urbanos, a especulação imobiliária (com forte influência sobre o planejamento - ou o desplanejamento - físico-territorial; os conflitos sobre o uso do solo, configurados pelas invasões urbanas em áreas de mananciais e áreas industriais e pela ocupação econômica em regiões de preservação ambiental; as deficientes soluções de transporte metropolitano e a elevada proporção de veículos por habitantes e área, congestionando a estrutura viária existente, prejudicando a mobilidade e acessibilidade, com a multiplicação de pontos de estrangulamento. 
No meio ambiente, as situações mais problemáticas dizem respeito ao destino e tratamento de resíduos (esgoto sanitário - não há um rio que passe pela RMC não poluído - e lixo urbano - esgotamento da Caximba, demandando solução que passa por um novo arranjo institucional metropolitano); disponibilidade de água dos mananciais, que vem demandando crescentes investimentos na captação e na preservação de reservas e áreas de mananciais; deslocamento da ocupação urbana e econômica atraída pelo Contorno Leste, avançando sobre região de mananciais, com impactos degradantes sobre a bacia de captação dos reservatórios; situações críticas de poluição aérea no centro de Curitiba, Araucária e Rodovia dos Minérios (Norte), associada à atividade industrial e ao trânsito, com impacto em doenças respiratórias.

A avaliação negativa do ambiente institucional está relacionada com esses dois direcionadores, com as piores situações detectadas na condição frágil de fiscalização e cumprimento da legislação de uso do solo e meio ambiente, sobretudo confrontados com interesses da especulação imobiliária enraizados nos poderes executivos e legislativos municipais (há municípios da coroa metropolitana nos quais tanto o prefeito como os vereadores têm participação em empreendimentos imobiliários); pouca participação na gestão municipal e regional (com soluções tecnocráticas, supostamente neutras, definindo o futuro da cidade, mantendo a população apenas como alvo das políticas urbanas); condição desfavorável das finanças municipais, sobretudo de municípios das coroas metropolitanas em que há nítida desproporção entre população e demandas sociais e capacidade de oferta, demandando a formação de consórcios metropolitanos; clima instável das alianças institucionais; fraco desempenho das instituições de fomento regional.

Um quarto direcionador em posição menos favorável é a condição social, onde os pontos mais críticos apontados foram: política habitacional para população de baixa renda (inferior a 3 salários mínimos) deficiente e incapaz de dar conta ao fluxo de imigrantes da região, provocando precariedade da ocupação de solo e condições de sub-habitação em loteamentos irregulares (favelas e invasões); crescente percepção da insegurança associada a diferenças de renda e condição de vida, falta de perspectiva para a mobilidade social e desemprego (crimes contra a propriedade); elevado índice de acidentes de trânsito; problemas de falta de oferta de água residencial e baixo índice de coleta e tratamento de esgoto; concentração dos equipamentos sociais, com diferentes níveis de oferta e qualidade entre o pólo e a periferia metropolitana. 
Dos demais direcionadores avaliados chama atenção, sobretudo na comparação com outras metrópoles do centro sul brasileiro, o reduzido desempenho da competitividade tecnológica, associado às deficiências da base empresarial local, (uma vez que a base econômica da região é dominada por grupos multinacionais), e a incipiência do sistema regional de ciência, tecnologia e inovação (C\&T\&I) - presença de poucas instituições fortes, clima instável de interação e reduzida conexão entre as instituições ponte de pesquisa e produção, apesar de todo recente esforço em consolidar uma rede de C\&T\&I no Paraná, focado na RMC.

À guisa de conclusão, pode-se destacar alguns pontos.

Apesar de um desempenho competitivo sistêmico que, na média dos direcionadores e das diferentes realidades sub-regionais (diferenças entre o município pólo, municípios das coroas metropolitanas e os anéis metropolitanos - áreas não conurbadas), tem sido favorável a análise, confirmando o estigma de metrópole dividida (que aliás não é um estigma exclusivo de Curitiba, mas presente em todas as metrópoles latino-americanas e na maioria das metrópoles mundiais). A Curitiba dividida é reforçada pelas dicotomias das áreas urbanas organizadas e valorizadas ao lado de áreas desestruturadas e com ordenamento precário, sobretudo em regiões próximas de mananciais, da distribuição concentrada dos equipamentos sociais e dos persistentes conflitos de uso de solo.

Outra questão diz respeito à sustentabilidade do desempenho econômico e social, que ameaça a competitividade sistêmica. Os maiores problemas de sustentabilidade são de ordem ambiental, social e urbana, sobretudo diante das elevadas taxas de crescimento demográfico impulsionadas pelas correntes migratórias do interior, pressionando as frágeis condições do meio ambiente (karst ao norte e mananciais a oeste e leste - serra do mar), a estrutura urbana mais precária dos municípios da coroa metropolitana e da periferia de Curitiba, agravando as críticas condições de habitação e segurança.

Vive-se em um período de expressivo crescimento econômico no município, com ampliação dos serviços sociais executivos: shoppings, hotelaria, escritórios de apoio ao comércio e à indústria. Esse momento de aquecimento da economia decorrente do fluxo de investimentos externos na região, limitado apenas pela conjuntura econômica nacional de stop-and-go, está encontrando outros limites, ressaltados pela metrópole dividida, demandando novas soluções institucionais e apresentando novos desafios para o desenvolvimento regional. 


\title{
RESUMO
}

Este ensaio tem como objetivo apoiar o debate recente sobre competitividade regional, com destaque à identificação de elementos chaves da competitividade sistêmica que possam orientar a formulação de políticas públicas e institucionais de desenvolvimento para a Região Metropolitana de Curitiba. A matriz de vantagens competitivas sistêmicas coloca-se como um instrumento analítico que permite uma avaliação rápida, sintética e objetiva da competitividade sistêmica regional, relevante para o apoio ao planejamento regional integrado. Para tanto se propõe, inicialmente, uma revisão teórica do debate sobre competitividade regional, enfatizando as novas vantagens competitivas locais, as economias de aglomeração, de aprendizado por interação e eficiência coletiva. A intenção, nesta primeira parte, é ressaltar os elementos (direcionadores e subfatores) que serão considerados na matriz, fornecendo ao aporte analítico um marco teórico mais consistente. Na seqüência, é apresentada a metodologia e a construção da matriz de vantagens competitivas sistêmicas, tomando como referência a Região Metropolitana de Curitiba, o que permite sustentar os destaques positivos e as questões mais críticas da competitividade sistêmica desta região.

Palavras-chave: desenvolvimento regional, competitividade sistêmica, metrópole, Curitiba.

\begin{abstract}
This essay aims at supporting the recent debate about regional competitiveness. It highlights the identification of key elements of systemic competitiveness that may guide the formulation of public and institutional development policies for the Metropolitan Region of Curitiba. The matrix of systemic competitive advantages appears as an analytical instrument for a quick, concise and objective analysis of regional systemic competitiveness, which is relevant to support the integrated regional planning. First it proposes a theoretical review of the debate about regional competitiveness, emphasizing new local competitive advantages, economies of agglomerations, of learning through integration and of collective efficiency. It is intended, in the first part, to point out the elements considered by the matrix (directional and sub-factors), providing a consistent theoretical mark to the analytical approach. Next the methodology and the construction of the systemic competitive advantages are presented, having the
\end{abstract}


Metropolitan Region of Curitiba as reference, making it possible to sustain the main positive points and the most crucial matters of systemic competitiveness of this region.

Key-words: regional development, systemic competitiveness, metropolis, Curitiba.

\section{REFERÊNCIAS}

ALBURQUERQUE, F. Competitividad internacional, estrategia empresarial y papel de las regiones. Serie Ensayos. n. 28. Santiago: Ilpes/Cepal, 1995.

AZZONI, C. R. (Org.). Onde produzir? Aplicações da teoria da localização no Brasil. São Paulo: IPE/USP, 1985.

Teoria da localização: uma análise crítica. São Paulo: FEA/USP, 1982.

BATALHA, M. O. Competitividade de cadeias agroindustriais: uma proposta metodológica de análise. Curitiba: IBQP : Gepai/UFSCAR, 2002.

BENKO, G. Economia, espaço e globalização na aurora do século XXI. São Paulo: Hucitec, 1996.

BOISIER, S. El difícil arte de hacer región. Cuzco: Centro de Estudios Regionales Andinos, 1992.

Sociedad del conocimiento: conocimiento social y gestión territorial. Santiago de Chile: Ider, 2001.

BORJA, J; CASTELLS, M. Local y global: la gestión de lãs ciudades em la era de la información. Habitat: Taurus Pensamiento, 1997.

COMEC. Referências para o Plano de Desenvolvimento Integrado da Região Metropolitana de Curitiba. Curitiba: Comec, 2001.

CONSÓRCIO SOGREAH/COBRAPE/GROUPE HUIT/IBQP. Diagnósticos setoriais do plano de desenvolvimento integrado da região metropolitana de Curitiba. Curitiba: Comec/Cobrape, 2002 (documentos de trabalho).

CUADRADO ROURA, J. R. Planteamientos y teorías dominantes sobre el crecimiento regional en Europa en las cuatro ultimas décadas. Revista Eure, Santiago, v. 21, n. 63, jun. 1995.

DINIZ, C. C. Global-local: interdependências e desigualdade ou notas para uma política tecnológica e industrial regionalizada no Brasil. BNDES/Finep/IE-UFRJ, Estudos Temáticos de Arranjos Produtivos, Nota Técnica 9, 2000. p. 4.

ESSER, Klaus, et al. Competitividad sistêmica: nuevo desafío para as empresas y la política. Revista de la Cepal, Santiago do Chile, n. 59, ago. 1996.

FIRKOWSKI, O. A nova territorialidade da indústria e o aglomerado metropolitano de Curitiba. São Paulo, 2001. Tese (Doutorado) - Universidade de São Paulo.

FUJITA, M.; KRUGMAN, P.; VENABLES, A. J. Economia espacial. São Paulo: Futura, 2002. 
GEM - Global Entrepreneurship Monitor. Curitiba: IBQP, 2001.

IBGE. Censo Demográfico (2000). Tabulações Especiais. Rio de Janeiro: IBGE, 2002. 2002. Disponível em: <www.ibge.gov.br/cidadessat/default.php> Acesso em: jun./dez.

Pesquisa de informações básicas municipais. Disponível em: <www.ibge.gov.br/ perfil/index.htm> Acesso em: jun./dez. 2002a. Pesquisa nacional de amostra domiciliar (2001). Rio de Janeiro: IBGE, 2002b. Sistema IBGE de Recuperação Automática - Sidra. Disponível em: $<$ www.sidra.ibge.gov.br/bda> Acesso em: jun./dez. 2002.

KRUGMAN, P. Internacionalismo pop. Rio de Janeiro: Campus, 1997.

LIMA, C. A. Considerações sobre ocupações irregulares e parcelamento urbano em áreas de mananciais da região metropolitana de Curitiba. Desenvolvimento e Meio Ambiente, n. 3, p. 97-114, jan./jun. 2001.

MACEDO, M. Experiências de planejamento em contextos de integração econômica. Campinas, 1994. Tese (Doutorado) - Unicamp.

MAILLAT D.; QUEVIT, M.; SENN, L. Réseaux d'innovation et milieux innovateurs: un pari por le développement territorial. Neuchatel: Gremi-Edes, 1993.

MARKUSEN, A. Sticky places in slippery space: a typology of industrial districts. Economic Geography, n. 72, p. 293-313, 1996.

MCKINSEY e COMPANY; FIEMG. Cresce Minas: um projeto brasileiro. Belo Horizonte: FIEMG, 2000.

MONIR, Nasser, J. Jacksonville e a pedagogia da verdade. Curitiba: IPD, 2002.

MOURA, R.; KLEINKE, M. L. U. Modelo Curitiba: os riscos de uma cidade insustentável. In: ENCONTRO NACIONAL DA ANPUR, 8., 1999, Porto Alegre.

MOURA, R. Fragilidades de um modelo. Curitiba: Ipardes, 2000. Mimeog.

Regulación de uso del suelo urbano: discusión sobre el caso de Curitiba.

Desenvolvimento e Meio Ambiente, n. 3, p. 115-124, jan./jun. 2001.

OLIVEIRA, D. A política de planejamento urbano: o caso de Curitiba. Campinas, 1995. Tese (Doutorado) - Unicamp.

PEREIRA, G. A natureza (dos) nos fatos urbanos: produção do espaço e degradação ambiental. Desenvolvimento e Meio Ambiente, n. 3, p. 33-51, jan./jun. 2001.

PORTER, Michael E.; CHRISTENSEN, C. Roland. Microeconomic competitiveness: findings from the 1999. WEF. Executive Survey. World Economic Forum, 1999. Disponível em: <www.wef.org>.

PROKOPENKO, Joseph. Competition: an agenda for the 21 st Century. Genebra: International Labour Office, 2000.

SASSEN, S. Ciudades em la economia global: enfoques teóricos y metodológicos. Revista Eure, Santiago, v. 24, n. 71, mar. 1998.

SCOTT, A. J.; STORPER, M. Indústria de alta tecnologia e desenvolvimento regional: uma crítica e reconstrução teórica. Espaço e Debates, ano 8, n. 25, 1988. 
VAN DUREN, E.; MARTIN, L.; WESTGREN, R. Assessing the competitiveness of Canada's agrifood industry. Canadian Journal of Agricultural Economics, 39, 1991.

\section{ANEXO 1: MATRIZES DOS DIRECIONADORES E SUBFATORES DA COMPETITIVIDADE SISTÊMICA}

Tabela 1 - MATRIZ DE VANTAGENS COMPETITIVAS DA RMC, CONDIÇÕES DE INFRA-ESTRUTURA

\begin{tabular}{|c|c|c|c|c|c|c|c|}
\hline \multirow[b]{2}{*}{$\begin{array}{l}\text { Direcionador } \\
\text { Subfator }\end{array}$} & \multirow[b]{2}{*}{ Relevância } & \multirow[b]{2}{*}{ Avaliação } & \multirow[b]{2}{*}{ Nota } & \multicolumn{4}{|c|}{ Grau de Controle } \\
\hline & & & & $\begin{array}{c}\text { Firma } \\
\text { Instituição }\end{array}$ & Governo & Pouco & Não \\
\hline 1. Condições de Infra-Estrutura & 100 & & 112 & & & & \\
\hline Sistema de Comunicações & 25 & & 37 & & & & \\
\hline Telefonia Fixa & 6 & MF & 12 & & & & \\
\hline Telefonia Móvel & 6 & MF & 12 & & & & \\
\hline Rede Digital e Fibra Ótica & 7 & $\mathrm{~F}$ & 7 & & & & \\
\hline Acesso à Internet & 6 & $\mathrm{~F}$ & 6 & & & & \\
\hline Sistema de Transporte & 30 & & 20 & & & & \\
\hline Condiçôes de Logística e Transporte de Carga & 5 & $\mathrm{~F}$ & 5 & & & & \\
\hline Porto & 5 & $\mathrm{~N}$ & 0 & & & & \\
\hline Aeroporto & 5 & $\mathrm{~F}$ & 5 & & & & \\
\hline Ferrovias & 5 & $\mathrm{~N}$ & 0 & & & & \\
\hline Rodovias & 5 & $\mathrm{~F}$ & 5 & & & & \\
\hline Porto Seco & 5 & MF & 10 & & & & \\
\hline Energia & 25 & & 30 & & & & \\
\hline Energia Elétrica & 12 & MF & 24 & & & & \\
\hline Combustiveis & 6 & $\mathrm{~F}$ & 6 & & & & \\
\hline Gás Canalizado & 7 & $\mathrm{~N}$ & 0 & & & & \\
\hline Água para fins produtivos & 10 & $\mathrm{~F}$ & 10 & & & & \\
\hline Terrenos e Construção & 10 & & 10 & & & & \\
\hline $\begin{array}{l}\text { Áreas e Barracões Industriais em Locais com } \\
\text { Infra-estrutura }\end{array}$ & 5 & $\mathrm{~F}$ & 5 & & & & \\
\hline $\begin{array}{l}\text { Inrra-sirutura } \\
\text { Condominios Empresariais }\end{array}$ & 5 & $\mathrm{~F}$ & 5 & & & & \\
\hline
\end{tabular}

Tabela 2 - MATRIZ DE VANTAGENS COMPETITIVAS DA RMC, BASE EMPRESARIAL

\begin{tabular}{|c|c|c|c|c|c|c|c|}
\hline \multirow[b]{2}{*}{$\begin{array}{l}\text { Direcionador } \\
\text { Subfator }\end{array}$} & \multirow[b]{2}{*}{ Relevância } & \multirow[b]{2}{*}{ Avaliação } & \multirow[b]{2}{*}{ Nota } & \multicolumn{4}{|c|}{ Grau de Controle } \\
\hline & & & & $\begin{array}{c}\text { Firma } \\
\text { Instituição }\end{array}$ & Governo & Pouco & Não \\
\hline 2. Base Empresarial & 100 & & 70 & & & & \\
\hline Presença de firmas de classe mundial & 10 & MF & 20 & & & & \\
\hline Presença de firmas qualificadas/certificadas & 10 & $\mathrm{~F}$ & 10 & & & & \\
\hline Difusão de Modernas Técnicas de Gestão & 15 & $\mathrm{~F}$ & 15 & & & & \\
\hline Atualização Tecnológica do Parque Produtivo & 10 & $\mathrm{~N}$ & 0 & & & & \\
\hline Disponibilidade e Qualidade dos Fornecedores Locais & 20 & & -10 & & & & \\
\hline Fornecedores de Matéria Prima & 5 & $\mathrm{~N}$ & 0 & & & & \\
\hline Fornecedores de Máquinas e Equipamentos & 5 & MF & -10 & & & & \\
\hline Fornecedores de Peças e Componentes & 5 & $\mathrm{D}$ & -5 & & & & \\
\hline Fornecedores de Serviços Auxiliares & 5 & $\mathrm{~F}$ & 5 & & & & \\
\hline Empresas exportadoras & 15 & $\mathrm{~F}$ & 15 & & & & \\
\hline Rede de Empresas & 10 & $\mathrm{~F}$ & 10 & & & & \\
\hline Associativismo Empresarial & 10 & $\mathrm{~F}$ & 10 & & & & \\
\hline
\end{tabular}


Tabela 3 - MATRIZ DE VANTAGENS COMPETITIVAS DA RMC, CLIMA DE INVESTIMENTO

\begin{tabular}{|c|c|c|c|c|c|c|c|}
\hline \multirow[b]{2}{*}{$\begin{array}{l}\text { Direcionador } \\
\text { Subfator }\end{array}$} & \multirow[b]{2}{*}{ Relevância } & \multirow[b]{2}{*}{ Avaliação } & \multirow[b]{2}{*}{ Nota } & \multicolumn{4}{|c|}{ Grau de Controle } \\
\hline & & & & $\begin{array}{c}\text { Firma } \\
\text { Instituição }\end{array}$ & Governo & Pouco & Não \\
\hline 3. Clima de Investimento & 100 & & 100 & & & & \\
\hline Fluxo de Investimentos Recentes & 15 & MF & 30 & & & & \\
\hline Participação de Grupos Regionais no Fluxo de Investimentos & 10 & $\mathrm{D}$ & -10 & & & & \\
\hline Reinvestimento de Empresas Instaladas na Região & 10 & MF & 20 & & & & \\
\hline $\begin{array}{l}\text { Relacionamento entre Empreendedores e Base Produtiva } \\
\text { Local }\end{array}$ & 15 & $\mathrm{~N}$ & 0 & & & & \\
\hline Empreendedorismo & 15 & MF & 30 & & & & \\
\hline Instrumentos e Incentivos a Investimentos & 35 & & 30 & & & & \\
\hline Instrumentos de Incentivo Fiscal & 5 & MF & 10 & & & & \\
\hline Promoção e Marketing Regional & 5 & $\mathrm{~F}$ & 5 & & & & \\
\hline Instrumentos Financeiros & 5 & MF & 10 & & & & \\
\hline Facilidades de Acesso à Infra-Estrutura & 5 & $\mathrm{~F}$ & 5 & & & & \\
\hline $\begin{array}{l}\text { Informações e Atendimento a Novos } \\
\text { Investidores }\end{array}$ & 5 & $\mathrm{~F}$ & 5 & & & & \\
\hline Incentivos para Grupos Locais & 5 & $\mathrm{D}$ & -5 & & & & \\
\hline Agilidade, Facilidade e Custos à abertura de novas empresas & 5 & $\mathrm{~N}$ & 0 & & & & \\
\hline
\end{tabular}

Tabela 4 - MATRIZ DE VANTAGENS COMPETITIVAS DA RMC, MERCADO

\begin{tabular}{|c|c|c|c|c|c|c|c|}
\hline \multirow[b]{2}{*}{$\begin{array}{l}\text { Direcionador } \\
\text { Subfator }\end{array}$} & \multirow[b]{2}{*}{ Relevância } & \multirow[b]{2}{*}{ Avaliação } & \multirow{2}{*}{$\begin{array}{l}\text { Nota } \\
\text { Direcionador } \\
\text { Subfator }\end{array}$} & \multicolumn{4}{|c|}{ Grau de Controle } \\
\hline & & & & $\begin{array}{c}\text { Firma } \\
\text { Instituição }\end{array}$ & Governo & Pouco & Não \\
\hline 4. Mercado & 100 & & 75 & & & & \\
\hline Renda & 35 & & 15 & & & & \\
\hline Renda per capita & 10 & $\mathbf{F}$ & 10 & & & & \\
\hline Índice do Poder de Compra Local & 5 & $\mathbf{F}$ & 5 & & & & \\
\hline Distribuição de Renda & 10 & $\mathbf{N}$ & $\mathbf{0}$ & & & & \\
\hline Famílias acima da linha da Pobreza & 5 & $\mathbf{N}$ & 0 & & & & \\
\hline Mercado Regional & 35 & & 35 & & & & \\
\hline Difusão de Bens de Consumo & 10 & MF & 20 & & & & \\
\hline Concentração do Mercado Regional & 5 & D & -5 & & & & \\
\hline Especialização do Mercado Regional & 5 & $\mathbf{F}$ & 5 & & & & \\
\hline Área de Influência & 5 & $\mathbf{F}$ & 5 & & & & \\
\hline Acesso a Mercados Nacionais/Internacionais & 5 & $\mathbf{F}$ & 5 & & & & \\
\hline Marcas de Empresas da Região & 5 & $\mathbf{F}$ & 5 & & & & \\
\hline Estrutura Comercial & 15 & & 10 & & & & \\
\hline Sistemas de Venda e Distribuição & 5 & $\mathbf{F}$ & 5 & & & & \\
\hline Centros Comerciais & 5 & $\mathbf{F}$ & 5 & & & & \\
\hline Sistema de Informações Mercadológicas & 5 & $\mathbf{N}$ & 0 & & & & \\
\hline Turismo e Eventos & 20 & & 15 & & & & \\
\hline Fluxo e Dispêndio Turístico & 5 & MF & 10 & & & & \\
\hline Estrutura Turística & 5 & $\mathbf{F}$ & 5 & & & & \\
\hline Centros de Eventos e Exposição/Feiras & 5 & D & -5 & & & & \\
\hline Feiras e Eventos Empresariais & 5 & $\mathbf{F}$ & 5 & & & & \\
\hline
\end{tabular}


Tabela 5 - MATRIZ DE VANTAGENS COMPETITIVAS DA RMC, ESTRUTURA URBANA

\begin{tabular}{|c|c|c|c|c|c|c|c|}
\hline \multirow[b]{2}{*}{$\begin{array}{l}\text { Direcionador } \\
\text { Subfator }\end{array}$} & \multirow[b]{2}{*}{ Relevância } & \multirow[b]{2}{*}{ Avaliação } & \multirow[b]{2}{*}{ Nota } & \multicolumn{4}{|c|}{ Grau de Controle } \\
\hline & & & & $\underset{\text { Instituição }}{\text { Firma }}$ & Governo & Pouco & Não \\
\hline $\begin{array}{l}\text { 5. Estrutura Urbana } \\
\text { Uso do Solo }\end{array}$ & $\begin{array}{c}100 \\
60\end{array}$ & & $\begin{array}{l}-40 \\
-45\end{array}$ & & & & \\
\hline Disponibilidade e Acesso a Terrenos Urbanos & 10 & MD & -20 & & & & \\
\hline Distribuição da Terra Urbana & 5 & $\mathrm{~F}$ & 5 & & & & \\
\hline Recuperação de áreas deterioradas & 10 & $\mathrm{~F}$ & 10 & & & & \\
\hline Especulação Imobiliária & 10 & $\mathrm{D}$ & -10 & & & & \\
\hline Pressões e Conflitos no uso do solo & 25 & & -30 & & & & \\
\hline Conflito Uso Rural X Urbano & 5 & $\mathrm{~N}$ & 0 & & & & \\
\hline Conflito Uso Rural X Ambiental & 5 & $\mathrm{D}$ & -5 & & & & \\
\hline Conflito Uso Industrial X Residencial & 5 & $\mathrm{D}$ & -5 & & & & \\
\hline Conflito Uso Industrial X Ambiental & 5 & MD & -10 & & & & \\
\hline Conflito Uso Urbano X Ambiental & 5 & MD & -10 & & & & \\
\hline Mobilidade e Condições de Acessibilidade & 40 & & 5 & & & & \\
\hline Qualidade e Oferta da Estrutura Viária & 10 & $\mathrm{~F}$ & 10 & & & & \\
\hline Transporte Coletivo Urbano & 10 & $\mathrm{~F}$ & 10 & & & & \\
\hline Transporte Coletivo Metropolitano & 10 & $\mathrm{D}$ & -10 & & & & \\
\hline Tempo de Deslocamento & 5 & $\mathrm{~N}$ & 0 & & & & \\
\hline Veículos por população e área & 5 & $\mathrm{D}$ & -5 & & & & \\
\hline
\end{tabular}

Tabela 6 -MATRIZ DE VANTAGENS COMPETITIVAS DA RMC, CONDIÇÕES SOCIAIS

\begin{tabular}{|c|c|c|c|c|c|c|c|}
\hline \multirow[b]{2}{*}{$\begin{array}{l}\text { Direcionador } \\
\text { Subfator }\end{array}$} & \multirow[b]{2}{*}{ Relevância } & \multirow[b]{2}{*}{ Avaliação } & \multirow{2}{*}{$\begin{array}{c}\text { Nota } \\
\text { Direcionador } \\
\text { Subfator }\end{array}$} & \multicolumn{4}{|c|}{ Grau de Controle } \\
\hline & & & & $\begin{array}{c}\text { Firma } \\
\text { Instituição }\end{array}$ & Governo & Pouco & Não \\
\hline 6. Condições Sociais & 100 & & 10 & & & & \\
\hline Habitação & 20 & & -2 & & & & \\
\hline Evolução de Alvarás para construção & 4 & $\mathrm{~F}$ & 4 & & & & \\
\hline Oferta de Habitação Popular & 4 & MD & -8 & & & & \\
\hline Densidade de Moradores & 4 & $\mathrm{~F}$ & 4 & & & & \\
\hline Financiamento Habitacional & 4 & $\mathrm{D}$ & -4 & & & & \\
\hline Condomínios para Executivos & 4 & $\mathrm{~F}$ & 4 & & & & \\
\hline Saúde & 20 & & 10 & & & & \\
\hline Coeficiente de Mortalidade Infantil & 5 & $\mathrm{~N}$ & 0 & & & & \\
\hline Coeficiente de Morbidade por Doenças Infecto-Contagiosas & 5 & $\mathrm{~F}$ & 5 & & & & \\
\hline Qualidade da Rede de Saúde Pública & 5 & $\mathrm{~N}$ & 0 & & & & \\
\hline Serviços Especializados de Saúde & 5 & $\mathrm{~F}$ & 5 & & & & \\
\hline Saneamento & 20 & & 5 & & & & \\
\hline Oferta da Água residencial & 5 & $\mathrm{D}$ & -5 & & & & \\
\hline Domicilios ligados à rede de água & 5 & MF & 10 & & & & \\
\hline Domicilios ligados à rede de esgoto & 5 & $\mathrm{D}$ & -5 & & & & \\
\hline Domicilios atendidos c/ coleta de lixo & 5 & $\mathrm{~F}$ & 5 & & & & \\
\hline Cultura e Lazer & 10 & & 15 & & & & \\
\hline Áreas de Entretenimento e Lazer & 5 & MF & 10 & & & & \\
\hline Eventos culturais e esportivos & 5 & $\mathrm{~F}$ & 5 & & & & \\
\hline Segurança & 15 & & -20 & & & & \\
\hline Indice de Crimes Violentos & 5 & $\mathrm{D}$ & -5 & & & & \\
\hline Índice de Crimes contra a Propriedade & 5 & MD & -10 & & & & \\
\hline Acidentes automobilisticos & 5 & $\mathrm{D}$ & -5 & & & & \\
\hline Política Social & 15 & & 0 & & & & \\
\hline Rede de Protecão Social & 5 & $\mathrm{~F}$ & 5 & & & & \\
\hline Distribuição dos Equipamentos Sociais & 5 & MD & -10 & & & & \\
\hline Evolucão dos Gastos Sociais per capita & 5 & $\mathrm{~F}$ & 5 & & & & \\
\hline
\end{tabular}


Tabela 7 - MATRIZ DE VANTAGENS COMPETITIVAS DA RMC, BASE EDUCACIONAL

\begin{tabular}{|c|c|c|c|c|c|c|c|}
\hline \multirow[b]{2}{*}{$\begin{array}{l}\text { Direcionador } \\
\text { Subfator }\end{array}$} & \multirow[b]{2}{*}{ Relevância } & \multirow[b]{2}{*}{ Avaliação } & \multirow[b]{2}{*}{ Nota } & \multicolumn{4}{|c|}{ Grau de Controle } \\
\hline & & & & $\begin{array}{c}\text { Firma } \\
\text { Instituição }\end{array}$ & Governo & Pouco & Não \\
\hline 7. Base Educacional & 100 & & 80 & & & & \\
\hline Taxa de Alfabetização Funcional & 10 & $\mathrm{~F}$ & 10 & & & & \\
\hline Taxa de Escolarização $\left(1^{\circ}, 2^{\circ}\right.$ e $3^{\circ}$ graus $)$ & 10 & $\mathrm{~F}$ & 10 & & & & \\
\hline Anos de Estudo (população com mais de 15 anos) & 10 & $\mathrm{~F}$ & 10 & & & & \\
\hline Disponibilidade e Qualidade do Ensino Público Fundamental e & & & & & & & \\
\hline Médio & 10 & $\mathrm{~N}$ & 0 & & & & \\
\hline Disponibilidade e Qualidade do Ensino Privado Fundamental e & & & & & & & \\
\hline Médio & 5 & $\mathrm{~F}$ & 5 & & & & \\
\hline Oferta de Programas de Bolsa-Escola e Bolsa de Estudos & 5 & $\mathrm{D}$ & -5 & & & & \\
\hline Condições do Ensino Profissionalizante & 10 & MF & 20 & & & & \\
\hline Condições do Ensino Técnico e Pós-Médio & 10 & $\mathrm{~N}$ & 0 & & & & \\
\hline Condições do Ensino Superior & 10 & $\mathrm{~F}$ & 10 & & & & \\
\hline Disponibilidade e Qualidade dos Cursos de Ciências Exatas, & & & & & & & \\
\hline Físicas e Naturais & 5 & $\mathrm{~N}$ & 0 & & & & \\
\hline Oferta de Escolas Internacionais e de Idiomas & 5 & MF & 10 & & & & \\
\hline Oferta de Cursos de Treinamento Empresarial & 5 & $\mathrm{~F}$ & 5 & & & & \\
\hline Relacionamento Escola-Empresa & 5 & $\mathrm{~F}$ & 5 & & & & \\
\hline
\end{tabular}

Tabela 8 - MATRIZ DE VANTAGENS COMPETITIVAS DA RMC, CONDIÇÕES E RELAÇÕES DE TRABALHOÇ

\begin{tabular}{|c|c|c|c|c|c|c|c|}
\hline \multirow[b]{2}{*}{$\begin{array}{l}\text { Direcionador } \\
\text { Subfator }\end{array}$} & \multirow[b]{2}{*}{ Relevância } & \multirow[b]{2}{*}{ Avaliação } & \multirow[b]{2}{*}{ Nota } & \multicolumn{4}{|c|}{ Grau de Controle } \\
\hline & & & & $\begin{array}{c}\text { Firma } \\
\text { Instituição }\end{array}$ & Governo & Pouco & Não \\
\hline 8. Condições e Relações de Trabalho & 100 & & 30 & & & & \\
\hline Evolução da Ocupação & 10 & $\mathrm{~F}$ & 10 & & & & \\
\hline Taxa de Desemprego & 10 & $\mathrm{D}$ & -10 & & & & \\
\hline Evolução da Renda Média dos Trabalhadores Ocupados & 10 & $\mathrm{~N}$ & 0 & & & & \\
\hline Taxa de Formalidade do Emprego & 5 & $\mathrm{~F}$ & 5 & & & & \\
\hline Trabalhadores com Previdência Social & 10 & $\mathrm{~F}$ & 10 & & & & \\
\hline Plano de Benefícios ao Trabalhador & 5 & $\mathrm{~F}$ & 5 & & & & \\
\hline Qualificação/Especialização da Mão-de-Obra Local & 10 & $\mathrm{D}$ & -10 & & & & \\
\hline Programas de Educação e Desenvolvimento do Trabalhador & 5 & $\mathrm{~F}$ & 5 & & & & \\
\hline Participação na Gestão, Lucros e Resultados & 5 & $\mathrm{~F}$ & 5 & & & & \\
\hline Índice de Conflitos Sindicais & 10 & $\mathrm{~F}$ & 10 & & & & \\
\hline Índice de Conflitos Internos & 5 & $\mathrm{D}$ & -5 & & & & \\
\hline Índice de Acidentes de Trabalho & 5 & $\mathrm{D}$ & -5 & & & & \\
\hline Rotatividade dos Empregados & 5 & $\mathrm{~N}$ & 0 & & & & \\
\hline Índice de Absenteísmo & 5 & $\mathrm{MF}$ & 10 & & & & \\
\hline
\end{tabular}


Tabela 9 - MATRIZ DE VANTAGENS COMPETITIVAS DA RMC, SISTEMA DE CIÊNCIA E TECNOLOGIA

\begin{tabular}{|c|c|c|c|c|c|c|c|}
\hline \multirow[b]{2}{*}{$\begin{array}{l}\text { Direcionador } \\
\text { Subfator }\end{array}$} & \multirow[b]{2}{*}{ Relevância } & \multirow[b]{2}{*}{ Avaliação } & \multirow[b]{2}{*}{ Nota } & \multicolumn{4}{|c|}{ Grau de Controle } \\
\hline & & & & $\begin{array}{c}\text { Firma } \\
\text { Instituição }\end{array}$ & Governo & Pouco & Não \\
\hline 9. Sistema de Ciência e Tecnologia & 100 & & 50 & & & & \\
\hline Empresas & 35 & & 20 & & & & \\
\hline Participação da Produção de Bens de Média e Alta & 10 & & & & & & \\
\hline Tecnologia & & $\mathrm{F}$ & 10 & & & & \\
\hline Dispêndio em P\&D (Produtos e Processos) & 10 & MF & 20 & & & & \\
\hline Dispêndio em Especialização de Pessoal & 5 & $\mathrm{D}$ & -5 & & & & \\
\hline Patentes e Registro de Propriedade Intelectual & 5 & $\mathrm{D}$ & -5 & & & & \\
\hline Instituições de Ensino Superior & 5 & $\mathrm{~N}$ & 0 & & & & \\
\hline Grupos de Pesquisa & 20 & $\mathrm{~N}$ & 10 & & & & \\
\hline Oferta de Mestrado e Doutorado & 5 & $\mathrm{~F}$ & 5 & & & & \\
\hline Contratos Tecnológicos com empresas da região & 5 & $\mathrm{~F}$ & 5 & & & & \\
\hline Estrutura de C\&T & 10 & $\mathrm{~N}$ & 0 & & & & \\
\hline $\begin{array}{l}\text { Instituições de Pesquisa e Integração } \\
\text { Tecnológica }\end{array}$ & 45 & & 20 & & & & \\
\hline Instituições de Fomento em C\&T & 10 & $\mathrm{~F}$ & 10 & & & & \\
\hline Oferta e Qualidade dos Laboratórios & 10 & $\mathrm{~F}$ & 10 & & & & \\
\hline Centros de Metrologia e Normatização Técnica & 5 & D & -5 & & & & \\
\hline Serviços de Alta Tecnologia & 5 & $\mathrm{~N}$ & 0 & & & & \\
\hline Incubadoras e Parques Tecnológicos & 5 & D & -5 & & & & \\
\hline
\end{tabular}

Tabela 10 - MATRIZ DE VANTAGENS COMPETITIVAS DA RMC, MEIO AMBIENTE

\begin{tabular}{|c|c|c|c|c|c|c|c|}
\hline \multirow[b]{2}{*}{$\begin{array}{l}\text { Direcionador } \\
\text { Subfator }\end{array}$} & \multirow[b]{2}{*}{ Relevância } & \multirow[b]{2}{*}{ Avaliação } & \multirow[b]{2}{*}{ Nota } & \multicolumn{4}{|c|}{ Grau de Controle } \\
\hline & & & & $\underset{\text { Firma }}{\text { Instituição }}$ & Governo & Pouco & Não \\
\hline 10. Meio Ambiente & 100 & & -40 & & & & \\
\hline Áreas de Preservação Ambiental e Reservas Ambientais & 15 & $\mathrm{D}$ & -15 & & & & \\
\hline $\begin{array}{l}\text { Disponibilidade de Água dos Mananciais Superficiais e } \\
\text { Subterrâneos }\end{array}$ & 15 & $\mathrm{D}$ & -15 & & & & \\
\hline $\begin{array}{l}\text { Qualidade da Água dos Mananciais Superficiais e } \\
\text { Subterrâneos }\end{array}$ & 10 & $\mathrm{~F}$ & 10 & & & & \\
\hline Coleta e Tratamento de Esgoto Sanitário & 10 & MD & -20 & & & & \\
\hline Qualidade do Ar & 5 & $\mathrm{~F}$ & 5 & & & & \\
\hline Eficiência Energética & 5 & $\mathrm{~F}$ & 5 & & & & \\
\hline Propaganda Visual & 5 & $\mathrm{~N}$ & 0 & & & & \\
\hline Limpeza de vias urbanas e ajardinamento de ruas e praças & 5 & MF & 10 & & & & \\
\hline Resíduos Sólidos (Lixo) & 30 & & -20 & & & & \\
\hline Geração e Tratamento de Resíduos Industriais & 5 & $\mathrm{~N}$ & 0 & & & & \\
\hline Geração e Tratamento de Resíduos Urbanos & 5 & MD & -10 & & & & \\
\hline Local de disposição de Resíduos & 10 & $\mathrm{D}$ & -10 & & & & \\
\hline Reciclagem de Resíduos & 10 & $\mathrm{~N}$ & 0 & & & & \\
\hline
\end{tabular}


MACEDO, M. M.; MEINERS, W. E. M. de A. Matriz de vantagens competitivas...

Tabela 11 - MATRIZ DE VANTAGENS COMPETITIVAS DA RMC, AMBIENTE INSTITUCIONAL

\begin{tabular}{|c|c|c|c|c|c|c|c|}
\hline \multirow[b]{2}{*}{$\begin{array}{l}\text { Direcionador } \\
\text { Subfator }\end{array}$} & \multirow[b]{2}{*}{ Relevância } & \multirow[b]{2}{*}{ Avaliação } & \multirow[b]{2}{*}{ Nota } & \multicolumn{4}{|c|}{ Grau de Controle } \\
\hline & & & & $\begin{array}{c}\text { Firma } \\
\text { Instituição }\end{array}$ & Governo & Pouco & Não \\
\hline $\begin{array}{l}\text { 9. Sistema de Ciência e Tecnologia } \\
\text { Empresas }\end{array}$ & 100 & & 50 & & & & \\
\hline Empresas & 35 & & 20 & & & & \\
\hline Participação da Produção de Bens de Média e Alta & 10 & & & & & & \\
\hline Tecnologia & & $\mathrm{F}$ & 10 & & & & \\
\hline Dispêndio em P\&D (Produtos e Processos) & 10 & $\mathrm{MF}$ & 20 & & & & \\
\hline Dispêndio em Especialização de Pessoal & 5 & $\mathrm{D}$ & -5 & & & & \\
\hline Patentes e Registro de Propriedade Intelectual & 5 & D & -5 & & & & \\
\hline Instituiçōes de Ensino Superior & 5 & $\mathrm{~N}$ & 0 & & & & \\
\hline Grupos de Pesquisa & 20 & $\mathrm{~N}$ & 10 & & & & \\
\hline Oferta de Mestrado e Doutorado & 5 & $\mathrm{~F}$ & 5 & & & & \\
\hline Contratos Tecnológicos com empresas da região & 5 & $\mathrm{~F}$ & 5 & & & & \\
\hline Estrutura de C\&T & 10 & $\mathrm{~N}$ & 0 & & & & \\
\hline Instituições de Pesquisa e Integração & 45 & & 20 & & & & \\
\hline $\begin{array}{l}\text { Tecnologica } \\
\text { Instituiçōes de Fomento em C\&T }\end{array}$ & 10 & $\mathrm{~F}$ & 10 & & & & \\
\hline Oferta e Qualidade dos Laboratórios & 10 & $\mathrm{~F}$ & 10 & & & & \\
\hline Centros de Metrologia e Normatização Técnica & 5 & $\mathrm{D}$ & -5 & & & & \\
\hline Serviços de Alta Tecnologia & 5 & $\mathrm{~N}$ & 0 & & & & \\
\hline Incubadoras e Parques Tecnológicos & 5 & $\mathrm{D}$ & -5 & & & & \\
\hline
\end{tabular}

